\title{
Evaluating Dynamic Thermal Comfort under Demand Response Events: a Novel Model Compared against Fanger's PPD Model
}

\author{
Marika Vellei ${ }^{1}$, Jérôme Le Dréau ${ }^{1}$ \\ ${ }^{1}$ La Rochelle University, La Rochelle, France
}

\begin{abstract}
To evaluate the dynamic thermal environments induced by Demand Response (DR) events, researchers have so far mainly relied on the steady-state PMV/PPD method. In this paper, different types of set-point modulations in two case study buildings are used to evaluate Fanger's PPD predictions against those of a novel dynamic thermal comfort model. The new model is built on the conceptual frameworks of thermal alliesthesia and thermal habituation. It is shown that Fanger's model is not able to predict the pleasure and displeasure sides of the intermittent modulations. Based on the evaluation of the novel model, the intermittent modulations are found to be particularly beneficial for maintaining thermal comfort in buildings with a low-performance thermal envelope.
\end{abstract}

\section{Introduction}

Future electricity systems will see an increase in the share of intermittent renewable generation and a growing electrification of energy demand. To sustain these changes without investing in carbon-intensive traditional power plants and/or in expensive network reinforcements, they will need to increase their flexibility. Flexibility in electric power consumption can be inexpensively and efficiently secured via DR programs, which can be implemented at industrial, commercial and residential level. DR can be defined as - a concept describing an incentivizing of customers by costs, ecological information or others in order to initiate a change in their consumption or feed-in pattern (CEN-CENELEC-ETSI, 2012) - .

At residential level, thermal systems and hot water storage tanks have the largest flexibility potentials. They provide homes with an energy rather than a power service and, thus, the power drawn from the grid can be adjusted and shifted significantly in time without affecting the energy service (Gottwalt et al., 2011). To exploit the flexibility potential of electric heating and/or cooling systems, DRactivated smart thermostats are relatively easy and cheap to implement compared to other solutions, which usually involve the use of active storage systems or alternative fuel sources (Leduc, Daoud, and Le Bel, 2011). For these reasons, smart thermostats are likely to become the first residential appliance to offer significant DR capacity worldwide (Vanthournout et al., 2017). In France, it is estimated that $75 \%$ of all the electric thermal systems will be flexible by 2050 (Fournié et al., 2018).
Occupants' acceptance of smart thermostats depends on how their thermal comfort is affected by the dynamic thermal conditions induced during DR events. Current standards only offer indications on the maximum temperature changes allowed over certain periods (ASHRAE, 2017; ISO, 2005) and, thus, do not allow to directly compare different dynamic thermal environments. To evaluate such dynamic conditions, researchers have so far mainly relied on the traditional PMV/PPD method. Examples are: (Agapoff, Jandon, and Guiot, 2017; Le Dréau and Heiselberg, 2016; Leduc et al., 2011; Masy et al., 2015; Morales-Valdés, FloresTlacuahuac, and Zavala, 2014; Péan, Ortiz, and Salom, 2017; Da Silva, 2011; Weiß, Fulterer, and Knotzer, 2017). However, Fanger's model is derived from a steady-state heat balance equation (Fanger, 1972) and is, thus, mainly suited to predict thermal comfort under steady-state and/or slowly changing dynamic thermal conditions (Koelblen et al., 2018).

A novel model, which predicts the percentage of dissatisfied occupants (PPD) from the steady-state $P M V$ index, was recently proposed to evaluate occupants' thermal comfort under dynamic thermal environments (Vellei and Le Dréau, 2019). The new PPD index was built based on experimental data collected at the Indoor Environmental Quality Laboratory of the University of Sydney as part of a study investigating the comfort impact of DR events (Zhang, de Dear, and Candido, 2016). Among the recent literature of dynamic thermal comfort laboratory studies, this is the laboratory experiment employing the greatest number of participants (fifty-six students) exposed to the highest rates of temperature change (up to $30^{\circ} \mathrm{C} / \mathrm{h}$ ).

In this paper, the new model is applied for the first time to evaluate occupants' thermal comfort under different types of DR set-point control strategies in two case study buildings, which represent typical archetypes of old and new single-family houses in France. The simulated DR events are used for modulating the heating load in winter. The aim of the paper is twofold. Firstly, to show how the new proposed model is able to better account for the different dynamic thermal conditions introduced in the building. Secondly, to compare the new comfort predictions against the building energy performances under different types of DR events. 


\section{A novel dynamic thermal comfort model}

A novel statistical model to predict $P P D$ from the steadystate $P M V$ index was recently developed based on the conceptual frameworks of thermal alliesthesia and thermal habituation (Vellei and Le Dréau, 2019).

According to Cabanan, alliesthesia is - the property of a given stimulus to arouse pleasure or displeasure according to the internal state of the subject (Cabanac, 1979) - . Occupants can experience alliesthesia when undergoing a variation of any environmental and/or personal variable influencing thermal comfort. During DR events and depending on the type of emitter used, usually the air and/or the mean radiant temperature is varied. Positive alliesthesia, i.e. pleasure, is due to the temperature either decreasing, when occupants are on the warm side of the thermoneutral zone, or increasing, when occupants are on the cold side of the thermoneutral zone. For characterizing the whole-body steady-state thermal state of a person, the more general Fanger's PMV index can be used. The $P M V$ index takes into account the influence of all six thermal parameters (clothing, activity, air- and mean radiant temperature, air velocity and humidity). Negative alliesthesia then occurs when moving away from a $P M V$ equal to zero (thus exacerbating the thermoregulatory load-error) and positive alliesthesia when moving towards it (thus minimizing the thermoregulatory load-error). Alliesthesia is further characterized by $\left|\frac{\partial P M V}{\partial t}\right|$, the rate of change or gradient of $P M V$, which measures - in vote/h - the intensity of the alliesthesial effect at each thermal state. If the thermal state stays unchanged or changes very slowly neither a pleasant nor an unpleasant sensation arises. To model this state of indifferent sensation we set the additional level of no alliesthesia for $\left|\frac{\partial P M V}{\partial t}\right|<1$ vote/h. 1vote/h corresponds to a rate of change of the operative temperature of about $3^{\circ} \mathrm{C} / \mathrm{h}$, the other conditions (clothing, activity, air velocity and humidity) being constant. Thus, alliesthesia is a factor with three possible levels: positive, negative and no.

Under repeated exposure to either warm or cool stimuli, humans experience a form of non-associative learning, called habituation, which leads to a progressive reduction of the normal response (Rankin et al., 2009). The phenomenon of perceptual habituation has been already observed in several thermal comfort laboratory experiments (Arens, Zhang, and Huizenga, 2006a, 2006b; Parkinson and de Dear, 2017; Stevens and Stevens, 1960) and can be modelled by introducing a predictor, called exposure, which measures - in discomfort ${ }^{2}$ minutes how much and for how long (in minutes) PMV differs from zero. As an example, 50 discomfort $^{2}$ minutes corresponds to being exposed for about 60 minutes to a thermal state varying sinusoidally between a PMV of 0 and 2.

In the new model it is found that $P M V$, alliesthesia, $\left|\frac{\partial P M V}{\partial t}\right|$ and exposure significantly affect $P P D$, while Fanger's $P P D$ only depends on $P M V$ index. In Figure 1, only the case of exposure $=0$ discomfort ${ }^{2}$ minutes is shown since the temperature modulations studied in this paper are too short and limited in magnitude for eliciting a significant thermal habituation effect. From Figure 1 we can notice that for $\left|\frac{\partial P M V}{\partial t}\right|<1$ vote/h, i.e. no alliesthesia in yellow, the new model nearly coincides with Fanger's PPD. We can also observe that on the warm side $(P M V>0)$ the thermal comfort zone extends when the cooling gradients are faster, while on the cold side $(P M V<0)$ the thermal comfort zone has the opposite behaviour and shrinks as the temperature decreases faster. Also, in the case of positive alliesthesia and for a thermal environment that is rapidly changing (i.e. high values of $\left|\frac{\partial P M V}{\partial t}\right|$ ), the predicted percentage of dissatisfied occupants is less than $5 \%$, which is the minimum value obtainable using Fanger's PPD. This aligns well with the hypothesis of alliesthesia: "higher levels of occupant satisfaction in transient or textured thermal environments may be explained by the hedonic overtones from the alliesthesial effect" (Parkinson, de Dear, and Candido, 2012) -. A zoom between a PMV of -0.5 and 0.5 on the aggregated experimental data used to derive the model is provided in Figure 2; we can notice that the observed percentages of dissatisfied occupants get values lower than $5 \%$.

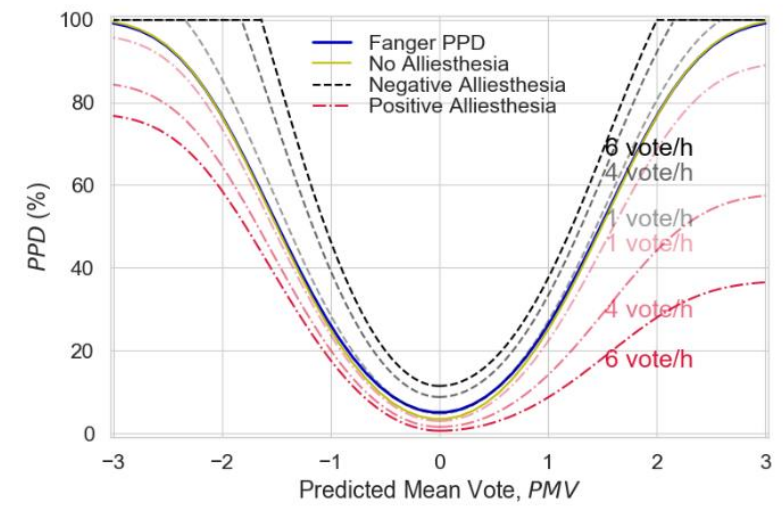

Figure 1: PPD as a function of PMV for exposure equal to 0 discomfort ${ }^{2}$ minutes and $\left|\frac{\partial P M V}{\partial t}\right|$ equal to 1,4 and 6 vote/ $h$.

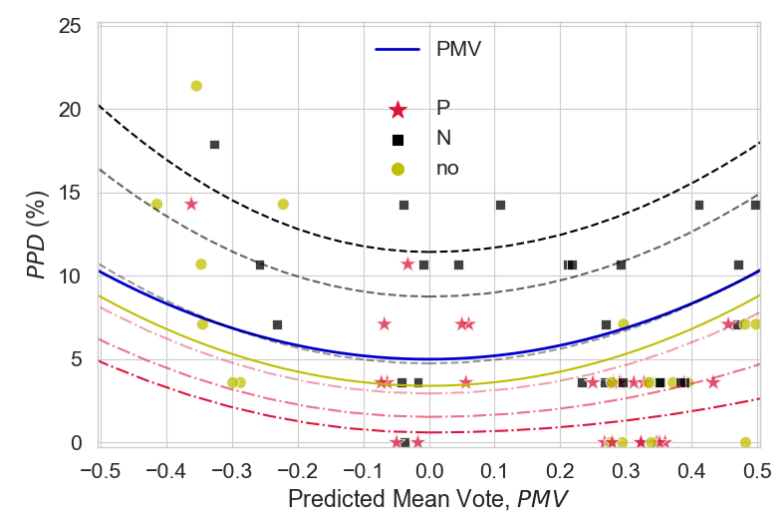

Figure 2: Observed and predicted percentage of dissatisfied occupants as a function of PMV for the three levels of positive $(P)$, negative $(N)$ and no alliesthesia. 


\section{Methods}

Two typical buildings are chosen according to the French building regulation (BR): BR 1982 (first building regulation) and BR 2012. The main thermal characteristics of the simulated buildings can be found in Table 1. They are insulated from the inside, a common feature in France, and are equipped with mechanical extraction, which is automatic for the old building (BR 1982) and humidity-controlled for the new building (BR 2012). Both buildings are single-family houses but they have different geometries and a floor area of 141 and 118 $\mathrm{m}^{2}$ for the old and the new building, respectively. The assumed occupation and internal loads scenarios result in a total sensible heat of around $5 \mathrm{MWh} /$ year, which corresponds to an average load of $4.8 \mathrm{~W} / \mathrm{m}^{2}$ floor. Due to these different characteristics, the space heating needs in Nancy, France (continental climate) are equal to 141 and $41 \mathrm{kWh} / \mathrm{m}^{2}$ floor $/$ year for the old and the new building, respectively. More details on the studied buildings can be found in (Le Dréau and Meulemans, 2018).

Table 1: Main thermal characteristics of the simulated buildings.

\begin{tabular}{|c|c|c|}
\hline $\begin{array}{c}\text { Thermal } \\
\text { characteristic }\end{array}$ & BR 1982 & BR 2012 \\
\hline $\begin{array}{l}\text { Insulation } \\
\text { Walls }\end{array}$ & $\begin{array}{c}4 \mathrm{~cm} \text { IWI } \\
\left(U=0.64 \mathrm{~W} / \mathrm{m}^{2} \mathrm{~K}\right)\end{array}$ & $\begin{array}{c}18 \mathrm{~cm} \mathrm{IWI} \\
\left(U=0.18 \mathrm{~W} / \mathrm{m}^{2} \mathrm{~K}\right)\end{array}$ \\
\hline $\begin{array}{l}\text { Insulation } \\
\text { Roof }\end{array}$ & $\begin{array}{c}8 \mathrm{~cm} \\
\left(U=0.58 \mathrm{~W} / \mathrm{m}^{2} \mathrm{~K}\right)\end{array}$ & $\begin{array}{c}28 \mathrm{~cm} \\
\left(U=0.13 \mathrm{~W} / \mathrm{m}^{2} \mathrm{~K}\right)\end{array}$ \\
\hline $\begin{array}{l}\text { Insulation } \\
\text { Floor }\end{array}$ & $\begin{array}{c}8 \mathrm{~cm} \\
\left(U=0.45 \mathrm{~W} / \mathrm{m}^{2} \mathrm{~K}\right)\end{array}$ & $\begin{array}{c}16 \mathrm{~cm} \\
\left(U=0.23 \mathrm{~W} / \mathrm{m}^{2} \mathrm{~K}\right)\end{array}$ \\
\hline Windows & $\begin{array}{c}\text { double glazing } \\
\left(U_{w}=3.1 \mathrm{~W} / \mathrm{m}^{2} \mathrm{~K}, g=0.75\right)\end{array}$ & $\begin{array}{c}\text { double glazing } \\
\left(U_{w}=1.5 \mathrm{~W} / \mathrm{m}^{2} \mathrm{~K}, \mathrm{~g}=0.63\right)\end{array}$ \\
\hline Thermal Mass & $\begin{array}{c}\text { medium } \\
\left(C_{m}=46 \mathrm{Wh} / \mathrm{m}^{2} \mathrm{~K}\right)\end{array}$ & $\begin{array}{c}\text { heavy } \\
\left(C_{m}=67 \mathrm{Wh} / \mathrm{m}^{2} \mathrm{~K}\right)\end{array}$ \\
\hline Infiltration & $0.35 \mathrm{ACH}$ & $0.12 \mathrm{ACH}$ \\
\hline HLC & $336 \mathrm{~W} / \mathrm{K}$ & $122 \mathrm{~W} / \mathrm{K}$ \\
\hline G & $0.93 \mathrm{~W} / \mathrm{m}^{3}$ heated $\mathrm{K}$ & $0.40 \mathrm{~W} / \mathrm{m}^{3}$ heated $\mathrm{K}$ \\
\hline$\tau_{\text {ISO } 13790}$ & $19 \mathrm{~h}$ & $65 \mathrm{~h}$ \\
\hline
\end{tabular}

Each building is modelled by 11 thermal zones using a Building Energy Simulation (BES) software (EnergyPlus 8.8). The results for the living rooms are here reported and analysed. The buildings are only simulated during the winter months of December, January and February for the year 2012 in Nancy, France. The simulation time-step is set to 1 minute.

Regarding the type of emitter, convectors are selected since they represent the most commonly used emitters in French all-electric residential dwellings (RTE, 2016). Convectors are located in each room of the house and are emitting heat by both radiation $(20 \%)$ and convection $(80 \%)$. Since the type of controller influences the dynamics of the building and thus the dynamic thermal comfort evaluation, a proportional controller (with a proportional band of $1^{\circ} \mathrm{C}$ ) is implemented in each convector, instead of the ideal controller proposed in (Le Dréau and Meulemans, 2018).

$5 \times 3 \times 2 \times 2$ different scenarios are simulated based on specific combinations of selected cases for each studied parameter, see Table 2. Each building is also simulated without DR event, which makes a total of 62 simulations.

The DR events - as implemented in the buildings - take the form of modulations of the space heating set-point temperature during the heating season. These modulations can be implemented in response to the typical two-rate TOU tariffs available nowadays in France. Upward modulations serve to store heat in the building during the off-peak hours, while downward modulations are useful to directly decrease the load during the peak hours.

Downward modulations - down - are realized from $21^{\circ} \mathrm{C}$ down to a minimum of $18^{\circ} \mathrm{C}$, while upward - up - are realized from $21^{\circ} \mathrm{C}$ up to a maximum of $24^{\circ} \mathrm{C}$, where $21^{\circ} \mathrm{C}$ is the normal set-point operative temperature. Modulations are of five different types:

- continuous - cont,

- intermittent by a succession of short modulations of 10 minutes with a period of rest of 20 minutes between them - int 10/20,

- intermittent by a succession of short modulations of 20 minutes with a period of rest of 10 minutes between them - int 20/10,

- intermittent by a succession of short modulations of 10 minutes with a period of rest of 10 minutes between them - int 10/10,

- intermittent by a succession of short modulations of 5 minutes with a period of rest of 5 minutes between them - int $5 / 5$.

Examples of both continuous and intermittent 2-hour modulations are given in Figure 3. Downward modulations of type int 10/20 have been already tested on 45000 households between January and February 2014 by the French company Voltalis in coordination with RTE (RTE, 2016)

Table 2: Selected cases for each studied parameter.

\begin{tabular}{|c|c|c|c|c|c|}
\hline Parameter & \multicolumn{5}{|c|}{ Cases } \\
\hline $\begin{array}{c}\text { Building } \\
\text { Regulation }\end{array}$ & 1982 & 2012 & & & \\
\hline $\begin{array}{c}\text { Modulation } \\
\text { Direction }\end{array}$ & down & up & & & \\
\hline $\begin{array}{c}\text { Modulation } \\
\text { Length }\end{array}$ & $1 / 2 \mathrm{~h}$ & $1 \mathrm{~h}$ & $2 \mathrm{~h}$ & & \\
\hline $\begin{array}{c}\text { Modulation } \\
\text { Type }\end{array}$ & cont & $\begin{array}{c}\text { int } \\
10 / 20\end{array}$ & $\begin{array}{c}\text { int } \\
20 / 10\end{array}$ & $\begin{array}{c}\text { int } \\
10 / 10\end{array}$ & $\begin{array}{c}\text { int } \\
5 / 5\end{array}$ \\
\hline
\end{tabular}

The DR events are only activated during 22 peak-days, which correspond to the days with the lowest mean daily temperatures during the three simulated winter months. The starting time of the peak hours is set at 6:00 pm, which coincides with the daily peak of the electrical load in winter in France (RTE, 2017). Modulations of either half an hour (1/2h), 1 hour (1h) or 2 hours (2h) are studied. 
Hence, the DR events start, at the earliest, at 4:00 pm in the case of the upward modulations and end, at the latest, at 8:00 pm in the case of the downward modulations.

For the calculation of the PMV index the air velocity is estimated at $0.1 \mathrm{~m} / \mathrm{s}$. The insulation value of clothing is assumed constant and equal to 1 clo, based on typical clothing in winter. The metabolic rate is set at 1.2 met.

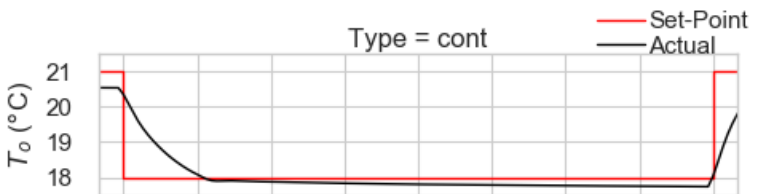

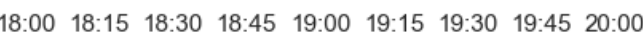

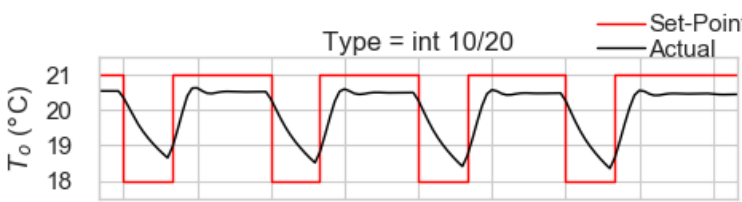

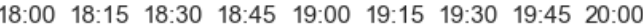

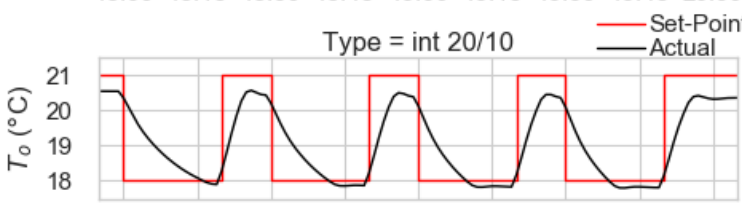

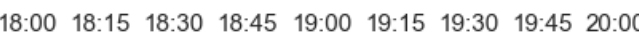

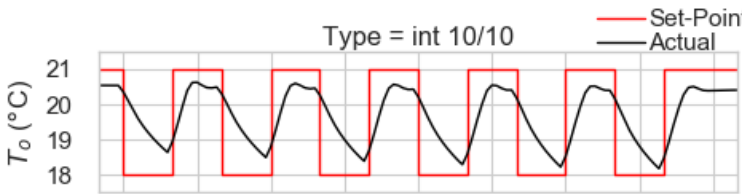

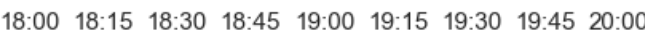
Time of Day

Figure 3: Examples of continuous and intermittent 2hour downward modulations during the coldest day of the year for the building BR 1982.

\section{Results}

\section{The new Model against Fanger's PPD Model}

Figure 4 and Figure 5 show examples of time series of the operative temperature $\left(T_{o}\right)$ and $P P D$ for both the downward and upward modulations implemented in BR 1982 and BR 2012, respectively. From Figure 4 it can be observed that, in the case of the downward modulation, Fanger's $P P D$ model underestimates discomfort/displeasure during the cooling down phase (negative alliesthesia in grey) and underestimates comfort/pleasure during the warming up phase (positive alliesthesia in pink). While, in the case of the upward modulation, there is first a positive alliesthesia phase due to the operative temperature increasing. Then, as the temperature continues to increase beyond the neutral setpoint temperature, negative alliesthesia is elicited. The following cooling down phase provokes positive alliesthesia until the neutral set-point temperature is reached. Then, the further decrease of the operative temperature elicits negative alliesthesia.
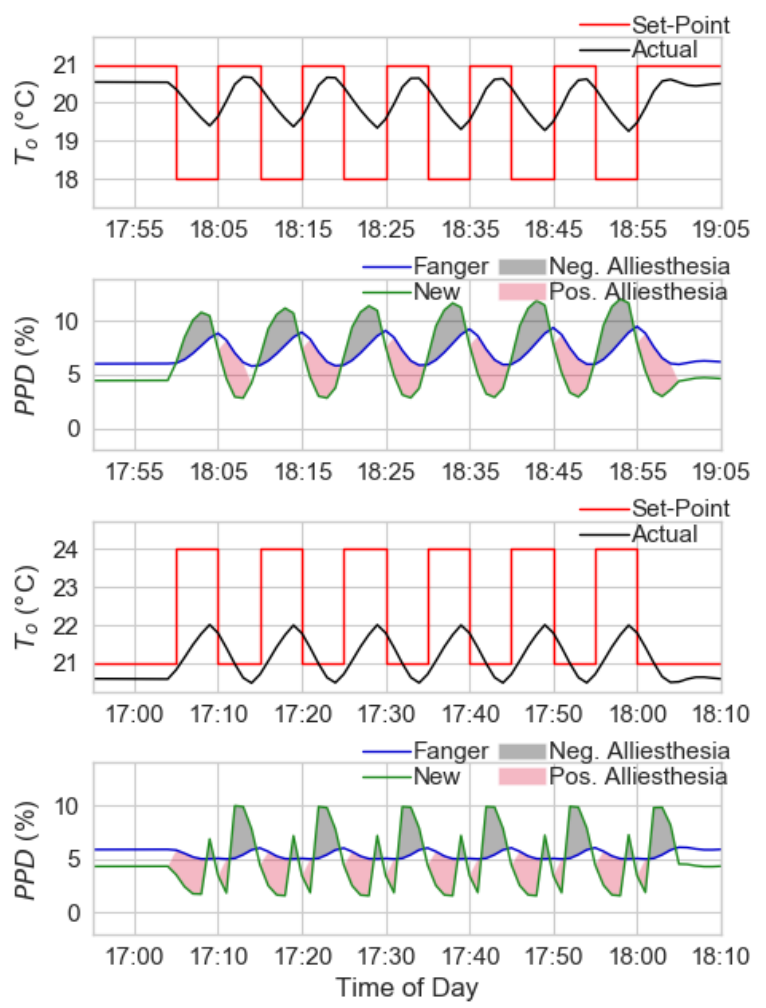

Figure 4: $T_{o}$ and PPD for both the cases of downward (above) and upward (below) modulations of length $1 \mathrm{~h}$ and type int 5/5. Only the coldest day of the year for the building BR 1982 is represented.
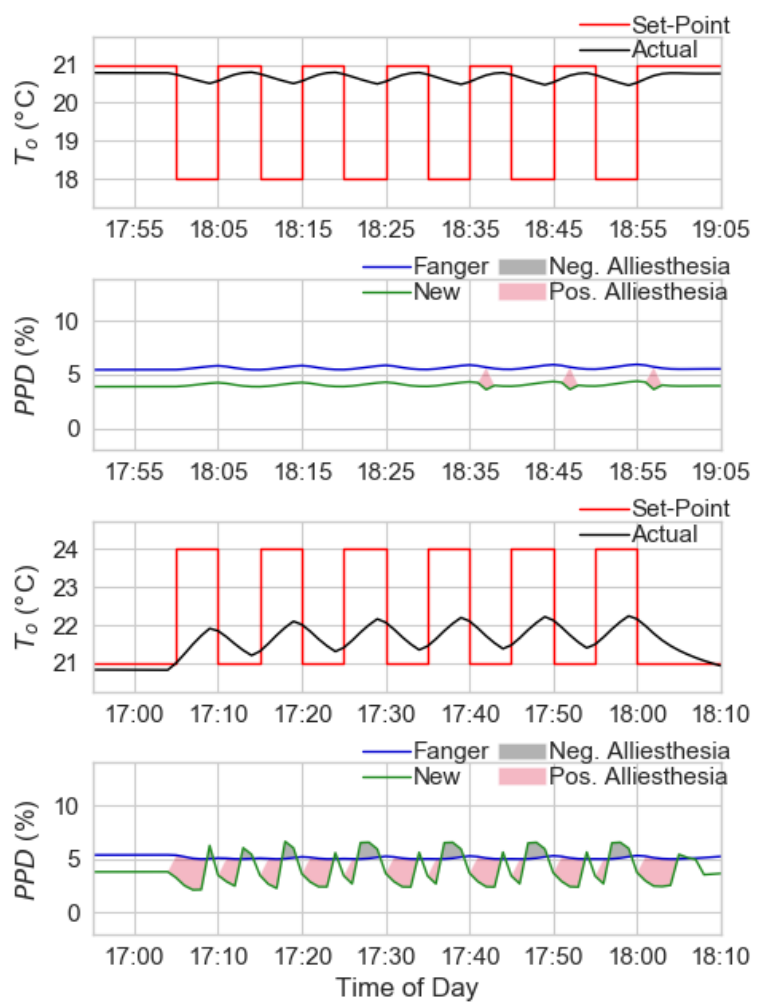

Figure 5: $T_{o}$ and PPD for both the cases of downward (above) and upward (below) modulations of length $1 \mathrm{~h}$ and type int 5/5. Only the coldest day of the year for the building BR 2012 is represented. 
The higher insulation and the heavier thermal mass of BR 2012 provide inertia against the temperature fluctuations and protect occupants from the negative alliesthesial effects associated with the temperatures decreasing during the downward modulation, as shown in Figure 5. In the case of the downward modulation, there are not big differences between Fanger's model and the new model since the rates of change of $P M V$ are nearly zero. During the upward modulation, the negative and positive alliesthesial effects associated with the temperature increasing and decreasing are more accentuated than during the downward modulation since the gradients of the temperature are stronger. Hence, the differences between Fanger's model and the new model are more pronounced for the upward modulation. Also, the positive alliesthesial effect is more marked than the negative alliesthesial effect.

For evaluating the indoor environment, the European standard EN 15251 specifies four different categories ( $I$, $I I$, III and IV), which are related to the level of expectations of the occupants (EN, 2007). This work considers Category II, which includes buildings with a normal level of expectation. For this category, the standard recommends that the level of thermal dissatisfaction of the occupants should always be below $10 \%$. This limit is highlighted in Figure 6, which shows both the empirical and theoretical cumulative distribution function of $P P D$ during the five different two-hour long downward modulations over the 22 days of DR activation in BR 1982. From Figure 6 it can be observed that the distribution of $P P D$ is much tighter for Fanger's model than for the new model. This reflects the inability of Fanger's model to detect the pleasure and displeasure thermal states associated to the positive and negative alliesthesial phases.

Significant differences in the distributions of the PPD values can be also observed in the boxplots of Figure 7 and Figure 8. In these boxplots, half of the data is distributed within the box and the data outside the whiskers represents outliers. BR 1982 is characterized by strong temperature gradients and, thus, the range of PPD values predicted by the new model is much larger than the range predicted by Fanger's model. This is especially true for the intermittent modulations: smaller is the period of the modulation stronger is the alliesthesial effect and, thus, more marked is the difference between the two models. Furthermore, the differences in the distribution are more marked for the case of the upward modulations, characterized by stronger gradients.

For BR 2012, the distributions of Fanger's PPD and the new PPD are comparable for the downward modulations. While, for the upward modulations, there are significant differences in the distributions due to the stronger cooling and warming gradients experienced. From Figure 7 and Figure 8 it can also be seen that the building envelope strongly influences the comfort of the occupants during the continuous downward modulations, with the new building performing better than the old building during any of the studied continuous downward modulations.
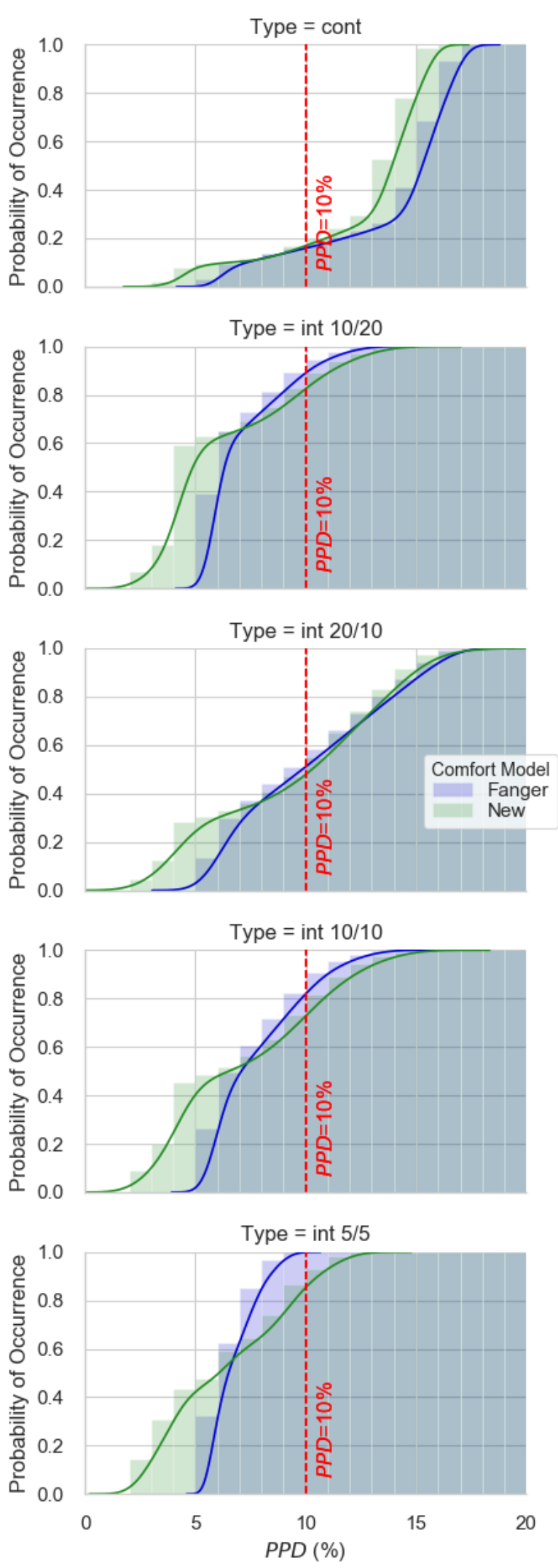

Figure 6: Empirical and theoretical cumulative distribution function of the PPD during the downward modulations of length $2 h$ in the building BR 1982. 
$B R=1982 \mid$ Length $=1 / 2 \mathrm{~h}$

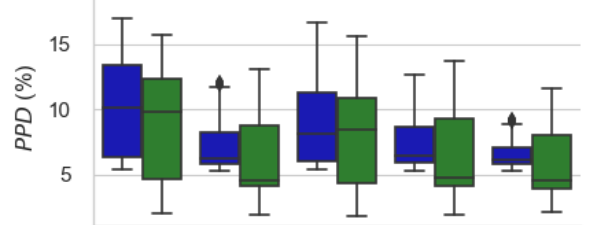

$B R=2012 \mid$ Length $=1 / 2 \mathrm{~h}$

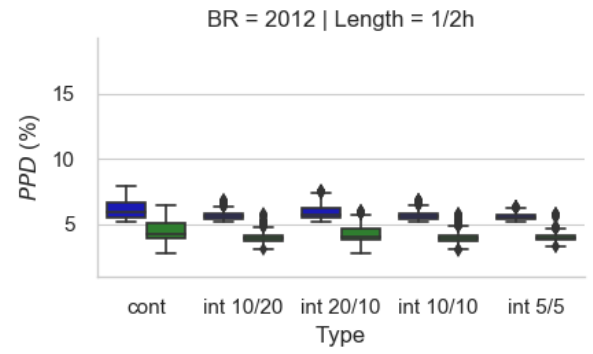

$\mathrm{BR}=1982 \mid$ Length $=1 \mathrm{~h}$

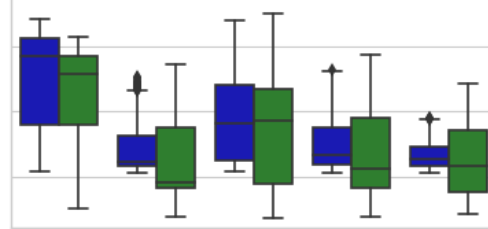

$\mathrm{BR}=2012 \mid$ Length $=1 \mathrm{~h}$

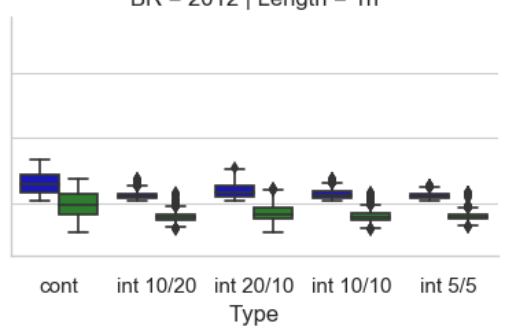

$\mathrm{BR}=1982 \mid$ Length $=2 \mathrm{~h}$

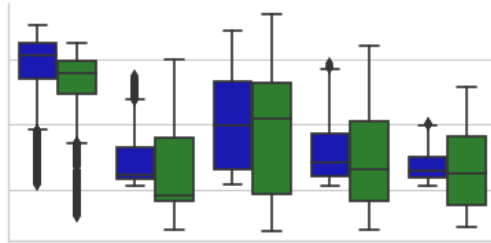

$\mathrm{BR}=2012 \mid$ Length $=2 \mathrm{~h} \quad \mathrm{New}$

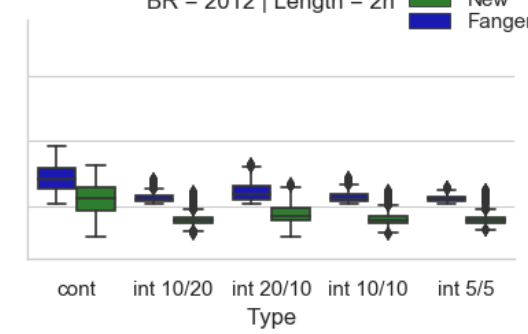

Figure 7: Boxplots of PPD during the downward modulations in the building BR 1982 (above) and BR 2012 (below).

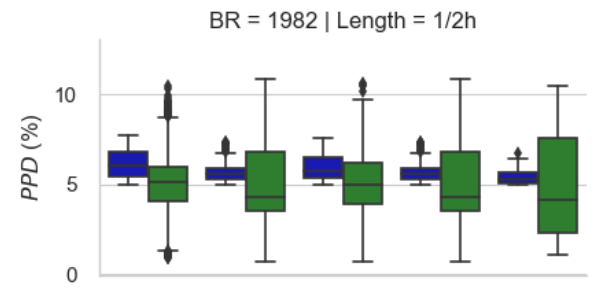

$B R=2012 \mid$ Length $=1 / 2 \mathrm{~h}$

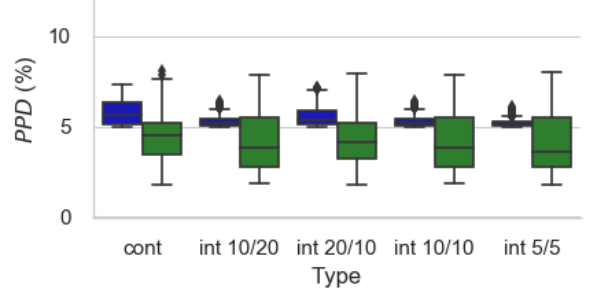

$\mathrm{BR}=1982 \mid$ Length $=1 \mathrm{~h}$

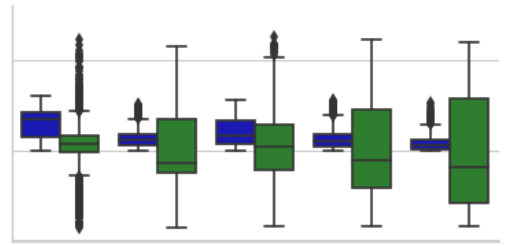

$\mathrm{BR}=2012 \mid$ Length $=1 \mathrm{~h}$

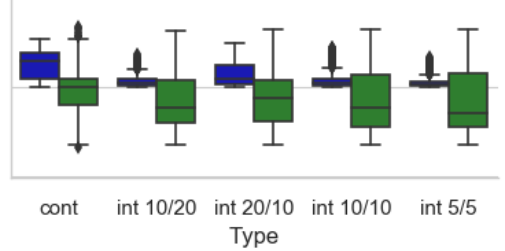

$\mathrm{BR}=1982 \mid$ Length $=2 \mathrm{~h}$

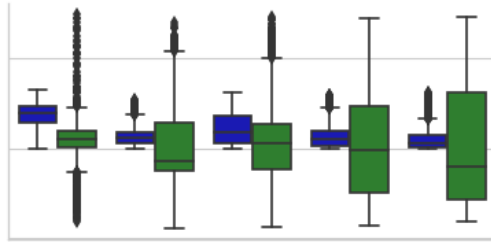

$\mathrm{BR}=2012 \mid$ Length $=2 \mathrm{~h}$ New

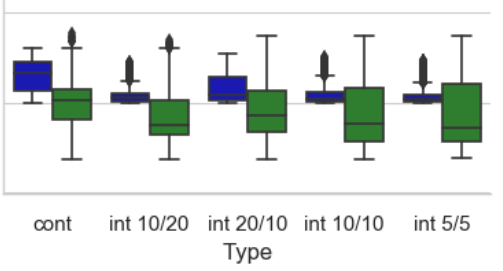

Figure 8: Boxplots of PPD during the upward modulations in the building BR 1982 (above) and BR 2012 (below).

New comfort predictions against buildings' energy performances

Two metrics are used for evaluating the studied modulation strategies:

- The whole heating energy consumption reduction $\Delta q_{\text {heating }}$ - in $\mathrm{Wh} / \mathrm{m}^{2}$ floor - calculated over the hours of modulations for the downward modulations and over the peak hours (from 6:00 pm to 08:00 pm) for the upward modulations. $\Delta q_{\text {heating }}$ is calculated throughout the 22 days of DR activation and with respect to the reference load curve, which is obtained by simulating the building without DR events.

- The mean and standard deviation of the PPD values predicted by the new model $\left(P P D_{\text {new }}\right)$. We consider only PPD values comprised between the start of the modulation and the 15 minutes after the end of it, throughout the 22 days of DR activation. This method complies with Method D of the Annex H of the EN ISO 7730 Standard (ISO, 2005), which can be used to evaluate comfort conditions over long exposures.

Figure 9 shows a scatterplot of $\Delta q_{\text {heating }}$ together with the mean and standard deviation (error bar) of $P P D_{\text {new }}$.
We can observe that the 2-hour long intermittent modulations are always associated with better comfort conditions than the continuous modulations. This is especially evident for the downward modulations in BR 1982. As an example, for BR 1982 the 1-hour downward continuous modulations (in bold) have a smaller energy shifted and a worse comfort than the 2-hour downward intermittent modulations of type int 20/10 (in bold), which makes the intermittent modulation of type int 20/10 the favourite DR strategy. This means that long but intermittent modulations can be preferable over the short but continuous modulations, both in terms of comfort and energy shifted. The intermittent downward modulations are particularly favourable for BR 1982, i.e. for buildings with a low-performance thermal envelope. 

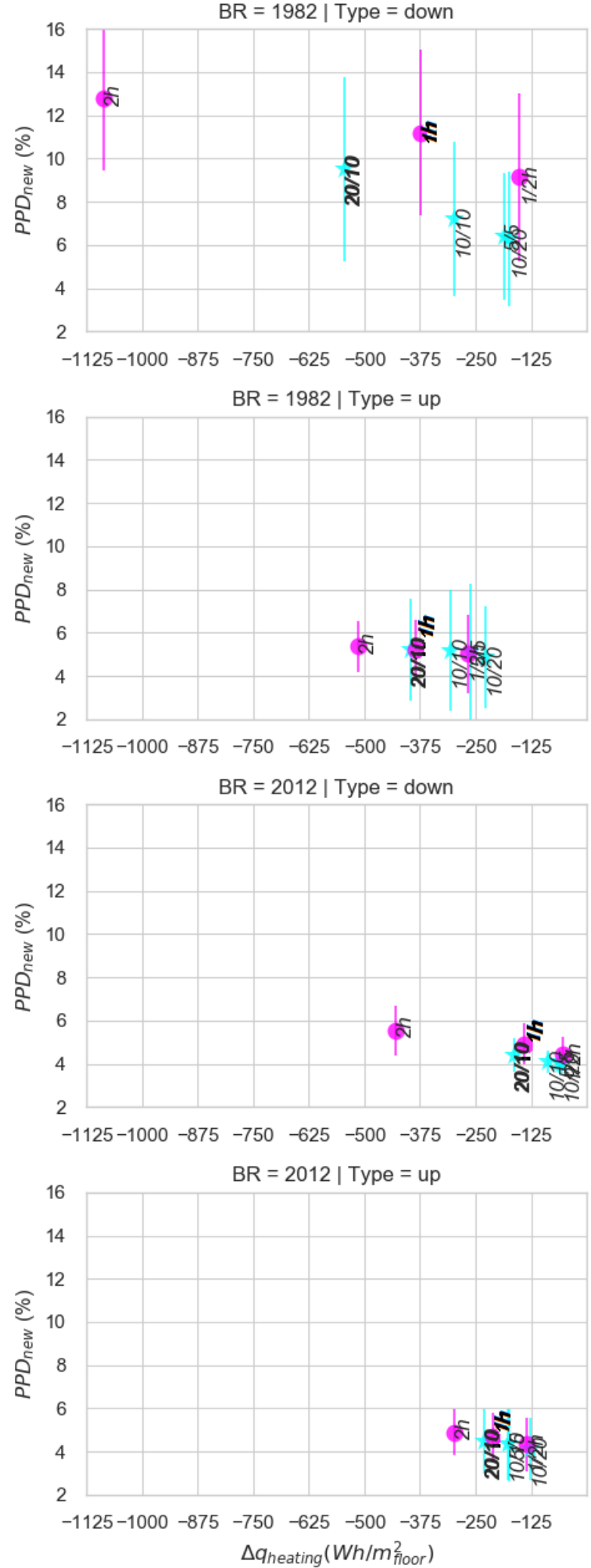

Figure 9: $P P D_{\text {new }}$ as a function of $\Delta q_{\text {heating }}$ for the different studied modulations. The continuous modulations are coloured in magenta and are annotated with their corresponding length, while the 2-hour intermittent modulations are coloured in cyan and are annotated with their corresponding type.

\section{Conclusion}

The new model presented in this paper makes it possible, for the first time, to account for thermal alliesthesia in the prediction of PPD from the PMV index and provides a new perspective for evaluating thermal comfort during DR events: the one of pleasure. The new PPD index is able to better account for the different dynamics thermal conditions introduced in the buildings during DR events. It is shown that Fanger's PPD index is failing to incorporate the pleasure and displeasure sides of the intermittent modulations. The use of the new model is particularly encouraged for the comfort evaluation of buildings with a low-performance thermal envelope, where stronger gradients of temperature can be found during DR modulations.

As expected, the comfort of old buildings is badly jeopardized during downward continuous modulations. In such case, the temperature fluctuations of longer but intermittent modulations are particularly beneficial since the pleasure given by the positive alliesthesial effect overcomes the displeasure associated with the negative alliesthesial phase.

The new model opens up unexplored possibilities for DR research and for investigating new way of optimizing the control of the set-point temperatures during DR events.

\section{Acknowledgement}

This research was funded by the French National Research Agency, CLEF project (ANR-17-CE22-000501).

\section{References}

Agapoff, S., Jandon, M., \& Guiot, T. (2017). Impact of a Tariff Based Heating Load Control on Energy, Comfort and Environment: A Parametric Study in Residential and Office Buildings. Proceedings from International SEEDS Conference 2017: Sustainable Ecological Engineering Design for Society. Leeds (UK).

Arens, E., Zhang, H., \& Huizenga, C. (2006a). Partialand Whole-Body Thermal Sensation and Comfort Part I: Uniform Environmental Conditions. Journal of Thermal Biology 31(1-2 SPEC. ISS.), 53-59.

Arens, E., Zhang, H., \& Huizenga, C. (2006b). Partialand Whole-Body Thermal Sensation and Comfort Part II: Non-Uniform Environmental Conditions. Journal of Thermal Biology 31(1-2 SPEC. ISS.), 60 66.

ASHRAE (2017). ANSI/ASHRAE Standard 55-2017 Thermal Environmental Conditions for Human Occupancy.

Cabanac, M. (1979). Sensory Pleasure. The Quarterly Review of Biology 54(1), 1-29.

CEN-CENELEC-ETSI (2012). Smart Grid Coordination Group - Sustainable Processes.

Le Dréau, J. \& Heiselberg, P. (2016). Energy Flexibility of Residential Buildings Using Short Term Heat Storage in the Thermal Mass. Energy 111, 991-1002. 
Le Dréau, J. \& Meulemans, J. (2018). Characterisation of the Flexibility Potential from Space Heating in French Residential Buildings. Proceedings from IBPC2018: 7th International Building Physics Conference. Syracuse (USA).

EN (2007). Indoor Environmental Input Parameters for Design and Assessment of Energy Performance of Buildings Addressing Indoor Air Quality, Thermal Environment, Lighting and Acoustics (EN 152512007).

Fanger, P. O. (1972). Thermal Comfort: Analysis and Applications in Environmental Engineering. McGraw-Hill.

Fournié, L., Chammas, M., Kassara, G., Attard, P., Khallouf, P., \& Hours, J.-H. (2018). ADEME Rapport Sur Les Données Utilisées Dans Le Cadre de l'étude "Trajectoires d'évolution Du Mix Électrique $2020-2060 »$.

Gottwalt, S., Ketter, W., Block, C., Collins, J., \& Weinhardt, C. (2011). Demand Side Management-A Simulation of Household Behavior under Variable Prices. Energy Policy 39(12), 8163-74.

ISO (2005). Ergonomics of the Thermal Environment Analytical Determination and Interpretation of Thermal Comfort Using Calculation of the PMV and PPD Indices and Local Thermal Comfort Criteria (ISO 7730 - 2005).

Koelblen, B., Psikuta, A., Bogdan, A., Annaheim, S., \& Rossi, R. M. (2018). Thermal Sensation Models: Validation and Sensitivity towards ThermoPhysiological Parameters. Building and Environment 130, 200-211.

Leduc, M.-A., Daoud, A., \& Le Bel, C. (2011). Developing Winter Residential Demand Response Strategies for Electric Space Heating. Proceedings from BS2011: 12th Conference of International Building Performance Simulation Association. Sydney (AU).

Masy, G., Georges, E., Verhelst, C., Lemort, V., \& André, P. (2015). Smart Grid Energy Flexible Buildings through the Use of Heat Pumps and Building Thermal Mass as Energy Storage in the Belgian Context. Science and Technology for the Built Environment 21(6), 800-811.

Morales-Valdés, P., Flores-Tlacuahuac, A., \& Zavala, V. M. (2014). Analyzing the Effects of Comfort Relaxation on Energy Demand Flexibility of Buildings: A Multiobjective Optimization Approach. Energy and Buildings 85, 416-26.

Parkinson, T. \& de Dear, R. (2017). Thermal Pleasure in Built Environments: Spatial Alliesthesia from Air Movement. Building Research \& Information 45(3),
320-35.

Parkinson, T., de Dear, R., \& Candido, C. (2012). Perception of Transient Thermal Environments: Pleasure and Alliesthesia. Proceedings from 7th Windsor Conference: The changing context of comfort in an unpredictable world. Windsor (UK).

Péan, T. Q., Ortiz, J., \& Salom, J. (2017). Impact of Demand-Side Management on Thermal Comfort and Energy Costs in a Residential NZEB. Buildings 7(2).

Rankin, C. H., Abrams, T., Barry, R. J., Bhatnagar, S., Clayton, D. F., Colombo, J., Coppola, G., Geyer, M. A., Glanzman, D. L., Marsland, S., McSweeney, F. K., Wilson, D. A., Wu, C. F., \& Thompson, R. F. (2009). Habituation Revisited: An Updated and Revised Description of the Behavioral Characteristics of Habituation. Neurobiology of Learning and Memory 92(2), 135-38.

RTE (2016). Évaluation Des Économies d'énergie et Des Effects de Bord Associés Aux Effacements de Consommation.

RTE (2017). Réseaux Électriques Intelligents: Valeur Économique, Environnementale et Déploiement d'ensemble.

Da Silva, D. (2011). 'Analyse de La Flexibilité Des Usages Électriques Résidentiels: Application Aux Usages Thermiques'. École Nationale Supérieure des Mines de Paris.

Stevens, J. C. \& Stevens, S. S. (1960). Warmth and Cold: Dynamics of Sensory Intensity. Journal of Experimental Psychology 60(3), 183-92.

Vanthournout, K., Gerard, H., Virag, A., Ectors, D., Bogaert, S., Claessens, S., Mulder, G., Breucker, S. De, Six, D., Viegand, J., \& Perret-gentil, M. (2017). Ecodesign Preparatory Study on Smart Appliances ( Lot 33 ) MEErP Tasks 1-6.

Vellei, M. \& Le Dréau, J. (2019). A Novel Model for Evaluating Dynamic Thermal Comfort under Demand Response Events. Building and Environment 160, 106-215.

Weiß, T., Fulterer, A. M., \& Knotzer, A. (2017). Energy Flexibility of Domestic Thermal Loads - a Building Typology Approach of the Residential Building Stock in Austria. Advances in Building Energy Research, 116.

Zhang, F., de Dear, R., \& Candido, C. (2016). Thermal Comfort during Temperature Cycles Induced by Direct Load Control Strategies of Peak Electricity Demand Management. Building and Environment 103, 9-20. 